\title{
Research of energy security problems of the Russian Federation considered by system- structural analysis
}

\author{
Elena Karanina ${ }^{1}$, and Natalya Abasheva ${ }^{2}$ \\ ${ }^{1}$ Vyatka State University, Moskovskaya str., 36, 610000 Kirov, Russia
}

\begin{abstract}
The authors of the article make an attempt to prove the need to apply a system-structural approach to studying an object in order to model its economic security system, demonstrated by the example of the energy industry. The authors conduct a consistent analysis of threats to Russia's energy security as the most important strategic subsystem influencing national security. Among the most significant threats analyzed in the article are: changes in the structure of demand for energy resources and the structure of their consumption in the world, the propensity of states to "green energy" and the introduction of energy-saving technologies. Increasing energy efficiency requirements also have a significant impact on the industry. However, the long time lag of the fourth energy transition described in the article makes it necessary to increase the efficiency of using our most important resources - gas and oil - to generate electricity, which will ensure the energy security of the state in the near future. Therefore, the authors examine the risks posed by the internal environment of the electric power industry, and prove possible solutions ensuring its economic security.
\end{abstract}

\section{Introduction}

Economic security, a complex and multifaceted phenomenon in the life of modern society, the basis of national security, requires a deep methodological study of both the essence of threats and risks affecting it, measures previously taken and formed to counter threats, developed both on macro- and micro- level and in industry. The authors have already paid much attention to the issues of ensuring economic security at the macro and micro levels in previous works $[1,2]$.

However, studying individual security subsystems in their specific, due to the specifics of the territory or industry and autonomous existence, is not able to consistently and effectively solve problems of functioning in a safe mode of the economy in general and its individual element, in particular. This, in turn, requires using such a phenomenon as security, a systemic-structural research method, implemented within the framework of a systematic approach. Its peculiarity is that the focus of attention is not on a specific autonomous element in the system, but on its characteristic from the position of what place it occupies in the context of influencing the performance of the system. Speaking about the system of economic security and the role of energy security in it, problems should be investigated not through the prism of the features and properties of the current energy system of the state, but 
understanding its place as an element in the system of national economic security as it affects the characteristics of the latter through interaction with other subsystems (legal, foreign trade, financial and budgetary, credit and banking, innovation and technology, information, etc.). At the same time, considering the problem of energy security as a system, and applying this approach, we must also structure it into separate elements. Each element contributes to the whole and must be managed a priori in a mode of minimizing threats to the energy industry. In authors' opinion, problems of today's risks in energy security management are largely related to the lack of an appropriate systematic approach to the management of the industry, both from the standpoint of national security in general, and industry security in particular. This article is devoted to studying these problems.

\section{Materials and Methods}

Many researchers have studied various aspects of economic security management. A great contribution was made by L.I. Abalkin, V.K. Senchagova, V.N. Anischenko, A.E. Gorodetsky, V.A. Zaitseva, A.V. Shestakova, I. Ya. Bogdanova, A.V. Vozzhenikova, etc.

The methodology of the indicator approach and risk management made it possible to develop a basis for diagnostics of various subsystems of economic security, which ensured the creation of the necessary information environment for developing solutions to counter threats. So, according to the indicator approach, the main questions are about the indicators used for diagnostics and their values. The most commonly used indicators are ones for assessing the financial condition and using financial resources. So, according to some authors [3-5], the most preferable indicators are for assessing liquidity, financial stability, turnover and profitability. On the basis of partial deviations from the threshold values, an integral indicator is used, while the researchers propose different approaches to determining the weight coefficients (scores) that determine the contribution of each indicator to the overall assessment of the level of economic security [6].

Another common approach to assessing the level of economic security is tested in risk management technology. The variety of methods can be summarized by qualitative and quantitative interpretation of risks. Some authors propose an integrated risk assessment methodology, where the materiality of risk is taken as a weighting indicator [7]. There are other approaches to assessing the level of economic security: an integrated approach that basically combines an indicator approach and an approach based on risk diagnostics; bankruptcy diagnostics and others.

However, no matter what degree of efficiency the diagnostic procedures is carried out, security management should obtain the results of the analysis of the object from the standpoint of countering threats, but also to give the complex nature of the latter, taking into account their dynamics in the context of both external and internal environment. This information will ensure the modeling of the operation of the object in question in the safety mode, which is impossible or, to a certain extent, flawed without a system-structural approach, that is, an approach to consider an object as a system, as a result of the interaction of its elements, and its understanding as a part of a larger system. Let us consider the problems of economic security of one strategic sector of the domestic economy - the energy sector. Various authors have suggested tools for ensuring energy security [8, 9].

First of all, it is necessary to define the security of the energy sector in the overall system of economic national security, relying on its complex nature. According to the "Strategy for the economic security of the Russian Federation for the period up to 2030," economic security is defined as the state of protection of the national economy from external and internal threats, which ensures the country's economic sovereignty, the unity of its economic space, conditions for the implementation of strategic national priorities of the Russian Federation. 
The most significant threats to national security are geopolitical tensions, trends towards further deepening of economic confrontation between states against the background of expansion of sanctions pressure, financial crisis changes of the world level and individual subnational entities that are becoming irreversible. However, threats associated with a new vision of the role of the energy sector in the economies of states, based on a tendency towards "green energy" and the introduction of energy-saving technologies, are beginning to appear more and more often. Considering the status of Russia as a producing power and the strategic importance of the energy industry, threats to national security are now generated by this leading sector of the economy. It is a source of revenue generation for the financial system of the state, a driver for the development of other industries, life support of citizens and, in general, plays the international role.

Based on the generally accepted understanding of the concept of energy security, this phenomenon should create conditions when threats are leveled for Russia, for its individual subjects and for the population. It is manifested in a deficit in the provision of energy resources in the standard volume and the required quality, there are no any interruptions in supply, risks of technogenic properties, potential damage to health, property and life of citizens. At the same time, it is this area of security that is largely responsible for the growth in the efficiency of using energy resources for all participants in energy relations.

Taking into account the role of the industry for the state and focusing on the methodology of a systematic approach, there is a need to carefully verify a strategy of the energy sector of the economy for the coming decades, paying attention to the changing situation in the demand for hydrocarbons.

\section{Results and Discussion}

It is advisable to analyze any subsystem of economic security focusing on an integrated approach in the study, which makes it possible to isolate individual elements of this subsystem and threats associated with them. It makes possible to form management decisions aimed to counter threats, taking into account the comprehensive nature of their influence. In the energy security system, it is also possible to define separate areas of management survey related to such groups of threats as technical and technological, natural and climatic, organizational and legal, political, economic, and managerial. Especially it is necessary to designate the practice of active mutual influence of these threats on each other. For example, a political crisis in interstate relations can have a negative impact on the solution of economic and technological problems, generating corresponding threats. The developing competition in the energy market has recently turned into open confrontation, up to the use of sanctions, violation of multilateral agreements, and speculative transactions in financial markets.

If we apply a historical approach to understand processes in the energy market today, it becomes clear that the problem of the security of this industry appeared in the era of the Middle East crisis, accompanied by a sharp decline in oil supplies from the Middle East. The resulting imbalance in the demand for energy resources of the economies of European countries and the United States and meeting this demand affected the dynamics of energy prices towards their growth. It sharply reduced the efficiency of their economies and the formation of economic potential in the face of confrontation with the socialist camp. As a result, to insure these risks, the International Energy Agency and the Organization of Petroleum Exporting Countries (OPEC) were created. An orientation was adopted towards a guaranteed supply of energy resources and the establishment of price parity, which reduced the risks of these consumers and had a political nature.

This industry largely determines problems of its economic security. At the beginning of the "value chain" and in its influence on other industries, it is capable of influencing their safety. In Russian Federation, which many years ago chose the raw material orientation of 
their economies, the monopoly of the energy industry was historically generated. Today it is becoming a serious risk to both national interests and the economic security of this industry, built on traditional sources of hydrocarbon raw materials.

An example of a particular focus on new challenges for the industry is the United States Energy Association's report "Post 9/11 National Energy Security." This report clearly draws a line that improving the energy security of the United States can be realized solely on the basis of diversification of energy sources.

Despite the fact that Russia has long recognized the risks of a raw material orientation of the economic model and annually reduces the share of oil and gas revenues in total revenues to the budget system (in the structure of the federal budget it is planned to reduce them to $35 \%$ by 2020), nevertheless, in Russia as an advanced energy power, the significance of this threat is excessively great.

The heightened US fears about the loss of world leadership, activation in increasing the capacity of shale oil production are accompanied by using political instruments of pressure on the processes in the domestic energy industry. In particular, we are talking about using various methods of restricting the access of domestic companies operating in the energy sector to modern technological solutions, the purchase of innovative equipment, and the prohibition of foreign investment in the industry. For example, the well-known example with ExxonMobil, when the latter, under the threat of sanctions, was forced to abandon the implementation of joint projects with Rosneft on the Arctic shelf.

An equally significant threat to the industry, and, consequently, to national security, is the movement towards "green energy". Such a trend in the future may lead to the abandonment of using classical hydrocarbon raw materials and correcting the structure and volume of demand in the energy market due to the environmental interests of states. Although this threat is a serious challenge, according to analysts and experts in this industry, it is of promising, distant nature.

Researchers from the Moscow School of Management SKOLKOVO have identified this trend as the fourth energy transition. This term refers to a serious, fundamental shift in the development of the global energy sector. V. Smil has proposed this term in order to describe changes in the consumption of energy resources, where its structure is used as the main criterion. The importance of each energy transition lies in the fact that it affects characteristics of energy supply and the state of the industry as a whole, but at the same time, having a direct impact on the dynamics of the entire economic model of society in its movement within the framework of scientific, technical and technological reform.

The first energy transition marked an increase in the share of coal in primary energy consumption from 5\% to 50\% (1840-1900). The second energy transition was based on an increase in oil consumption from $3 \%$ to $45 \%(1915-1975)$. However, the period of oil dominance was stopped by the oil crisis of the late 1970s. The third energy transition brought to the fore the interest in using natural gas, the share of which in the consumption of fossil fuels increased between 1930 and 2017 from $3 \%$ to $23 \%$. The fourth energy transition can be chronologically attributed to 2010 (after the accident at the Fukushima nuclear power plant), when the "Energiewende" concept gained wide popularity in Germany. This term was first used by the German Environmental Institute in the publication "Energy Turn. Growth and prosperity without oil and uranium" [10].

This work has aimed to substantiate that economic growth and guaranteed power supply is possible without using nuclear energy. Thus, the advantages of renewable energy sources and their role in the growth of energy efficiency were proven. Also, this approach provides for a strict adherence to principles of environmental friendliness, since it has a focus on decarbonizing electricity generation and reducing greenhouse gas emissions. Ongoing research in this area shows that due to a $40 \%$ reduction in emissions by 2020 and $80-95 \%$ by 2050 , this approach is strategically correct [11]. 
The fourth energy transition described above is undoubtedly associated with the development of new technologies. However, the transformation process can take quite a long time due to a number of factors. Let us try to assess some of them and start from the idea of electric vehicles that has gained popularity recently. The American company Tesla, which produces electric vehicles with an $\mathrm{AC}$ electric motor, has become an almost absolute monopoly in this area. The company's developers have found the most optimal energy efficiency: with a relatively small battery capacity, cars have the greatest range. However, the biggest problems of this technological solution are: from an economic standpoint - an expensive battery, and from an operational standpoint - the issue of charging it.

You can make simple calculations. Taking into account the car park in the world (more than 1.2 billion cars), the approximate energy requirements for a car with an electric motor (based on $100 \mathrm{~km}$ of $20 \mathrm{kWh}$ ), focusing on the annual mileage of electric vehicles available in the world (about 25 billion $\mathrm{km}$ ), electric vehicles will need 5000 billion kilowatts of electricity. To generate such an amount of electricity to charge cars, according to experts, we need 450 nuclear power plants or 400 coal-fired power plants or 4,000 hydroelectric power plants. Renewable energy sources can also be used.

However, taking into account the capacities available today, it is possible to get about 78 billion kWh per year from wind stations, and 38 billion from solar panels. Moreover, these energy sources are not constant. This will force them to have a certain "buffer" in the form of traditional energy sources, for example, coal, oil, gas. And the gas stations must also consume a certain amount of energy. From an environmental point of view, such an approach to energy sources for the operation of electric motors is justified, but from a technological and financial point of view, it will probably take a long time to solve the problem.

Modern society has long faced the problem of depletion of traditional fossil resources, but this raises other issues and risks. For example, the German project described above on the possibility of a complete transition to renewable energy sources led to the fact that its implementation as an experiment to abandon nuclear power plants in Germany, increased coal combustion.

Nevertheless, the process is underway, and the world is trying to replace fossil fuels, driven by changes in energy policy and the development of new technologies. However, the 4th energy transition can be delayed for a very long time. Even with the expected rapid development of renewable energy sources, only by 2040, under the most optimistic scenario, it will be possible to provide $35-50 \%$ of world electricity production and $19-25 \%$ of all electricity consumption.

Considering the long time lag of the described fourth energy transition (according to the scientists of the Energy Center of the Moscow School of Management SKOLKOVO, this period can cover 7-10 years), it is necessary to take into account the transformation of electricity markets and the need for serious adaptation of the country to this transition.

Therefore, within the framework of the implemented energy strategy of Russia, at the moment it is necessary to focus on improving the efficiency of using our most important resources - gas and oil - in order to generate electricity. In this regard, starting from the systemic and structural approach, it is necessary to move on to the analysis of individual subsystems in the country's energy security system.

The objective reasons for the emerging risks are currently associated with the strategic resource sources for generating electricity - oil and natural gas. According to existing estimates, approximately $39 \%$ of the world's electricity is currently produced on the basis of oil, $27 \%$ on the basis of coal, and $24 \%$ on natural gas [11].

Thus, traditional energy currently occupies approximately $90 \%$ of all energy capacities in the world. The Russian Federation today is one of the leading oil production countries, determining the supply of hydrocarbons on the market. The approximate annual volume of extracted crude oil is more than 0.5 billion tons; only about half of this volume is used for 
domestic consumption. On average, the profit per year from this resource is $\$ 170$ billion. However, the proven oil and gas resources in Russia are far from the highest in the world. According to research by British Petroleum, Russia's share is $5.3 \%$ of all world oil reserves, which is significantly lower than the reserves of Venezuela (18\%) and Saudi Arabia (16.1\%). Nevertheless, Russia is among the richest countries in oil. However, the nature of the use of resources is increasingly reflected in the availability of their extraction at the present time. Moreover, the factor of depletion of existing fields in development is playing an increasingly active role. The experts think that while maintaining the current level of production, the exhaustion of oil fields will peak in Russia in 23.5 years. For comparison: in Iran and Kuwait it will happen in 96 and 97 years, respectively. In the world, the exhaustion of this resource can occur in 54 years. A similar analysis for gas shows that Russia is the absolute leader in terms of available reserves, with 21 percent of all world reserves. Iran owns 15.9\%, Qatar $12 \%$ of the world's gas reserves.

If we analyze the dynamics of oil production in Russia for the period 1991-2019, it reached its maximum in 2019, despite the operation of the OPEC + agreement. According to Bloomberg estimates, in 2019 in Russia, 11.25 million barrels of oil were produced daily. According to the OPEC Annual Statistical Bulletin 2019, Russia ranks 2nd in the world in oil production after the United States. According to Rosstat, the cost of oil production (excluding taxes) at the current exchange rate of the USD RUB currency pair in the second quarter of 2019 amounted to 2508 rubles per barrel or $\$ 31.9$ at the average rate of the quarter. By comparison, Saudi Arabia and Kuwait's oil production costs are roughly $\$ 17.6$ per barrel, making it the lowest in the world, providing a competitive edge amid falling exchange-traded prices, according to IHS Markit, a consulting company. However, in the opinion of both domestic and foreign experts, large-scale oil and gas fields in their potential are being depleted, which reduces production volumes and necessitates additional financial investments in connection with the restoration of geological exploration, production of hardto-recover raw materials and using new mining technologies.

It leads to increasing the price of raw materials, and with an excess of its supply (according to various estimates, in February 2020, the excess supply on the oil market ranged from 500,000 to 800,000 barrels of oil per day daily), this can lead to serious losses for the industry. Thus, the most "expensive" new oil fields are located in the Arctic and the Far East. Even taking into account tax incentives, their cost is $\$ 50-55$ per barrel. This, in turn, affects electricity tariffs, and the latter affects the competitiveness of any domestic product. According to the Ministry of Energy, the break-even point for onshore oil projects averages $\$ 42$ per barrel of Brent grade, and for offshore production projects - \$ 44 per barrel. Thus, there is a question about the potential unprofitability of these projects, which can grow under the conditions of the current market factors for this raw material. An inventory of the recorded reserves of this type of raw material for the energy complex of the state revealed a loss ratio of about $50-65 \%$.

Taking into account the needs of the budget, the Russian Federation, having huge and gigantic deposits of oil and gas resources, should focus on their consistent development. However, this requires serious investments, and sometimes direct participation in projects of other countries which have the necessary technologies.

Let us consider the issue of the need for financial resources, which allows to finance more technologically advanced projects and reduce the cost of today's fuel resource, which is quite expensive for many consumers.

The costs of industrial consumers to pay for electricity in the cost structure are a serious factor in competitiveness. There should be no problems, according to the cited data on the reserves of our natural strategic resources, the volume of their production, the size of exports, especially if we take into account the cost of energy resources in the world. If our wholesale 
consumers of electricity pay $\$ 41$ for each megawatt, including VAT, in Germany it is $\$ 145$, in England - \$139, in China - \$104.

If we take the calculations for the machine-building sector of our economy, the share of electricity costs in the structure of the cost of goods produced in our country is just over $5 \%$, which is practically the same as in the UK, but significantly exceeds the level in Germany and China (approximately 3\%).

In the mining sector (except for fuel), the share in the prime cost is even lower $-3.1 \%$ (for comparison, in China it is more than $4 \%$, and in Germany - about $5 \%$ ). In the USA, Korea, Brazil, this figure reaches 9-10\% [11].

At the same time, in terms of energy intensity, our enterprises are seriously lagging behind foreign ones. For example, the engineering industry in Russia has an energy intensity indicator that is six times higher than the German one, the Chinese one - four times, in the extraction of natural resources (except for hydrocarbons) - 2.5 and 2 times, respectively. As a result, even at lower tariffs, higher energy intensity leads to serious financial costs for producers. Taking into account the "value chain", energy costs at each step of the calculation lead to a significant increase in the cost of the final product and a heavy burden on the consumer within the country. Besides, it reduces the competitiveness in the external market.

Within the framework of strategic planning by 2020 benchmarks were set for reducing the energy intensity of GDP by $40 \%$. However, according to the estimates of the Ministry of Economic Development, by 2019 this figure was only $9 \%$. Taking into account the current trend, the planned decrease in energy intensity can be obtained, according to experts, only by 2043.

Industrial consumers have chosen a different path. Wishing to reduce the cost of electricity, at a meeting of the commission of the Russian Union of Industrialists and Entrepreneurs on the electric power industry, they put forward the following ideas:

- a $50 \%$ reduction in payment for capacity on the wholesale electricity and capacity market;

- on refusal from further selection of projects for modernization of generating equipment;

- on the postponement of the competitive power take-off to 2026;

- on the introduction of a temporary moratorium on fines for late payment of energy resources.

According to the monitoring of payment discipline according to the Ministry of Energy, payments for electricity in June 2020 reached $97 \%$, which is $3 \%$ below the reported data in 2019. According to the reporting data for June 2020, the total debt for the supply of energy resources is about 280 billion rubles, including overdue - more than 158 billion, an increase of 25 percent compared to the previous year [12]. A similar situation accompanies the supply of thermal energy (in terms of the electricity industry) and gas supplies.

Of course, the problems of industrial enterprises economy in connection with the pandemic are understandable. However, the refusal to pay for capacity do not allow electricity producers to repair equipment, pay salaries to employees, pay taxes on time, ensure the protection of facilities, etc. A significant reduction in the costs of this designated purpose cause problems with financing repair work, and this, in turn, leads to the risk of accidents, failures in energy and heat supply to consumers, especially the population, social facilities, and, in general, affects Russia's energy security and the entire national security system. The development and processing of energy resources also require investments in new highperformance capacities, which reduce dependence on foreign technologies.

It is probably illogical to shift the entire burden of financing investments for energy suppliers onto consumers, as they also need financial sources to modernize their own capacities in order to reduce the energy intensity.

The high energy intensity of GDP means the ineffective structure of the economy and the predominance of raw materials industries in it. By the way, it should be noted that in 
generation, the most energy-intensive sector of the fuel and energy complex, it was possible to reduce fuel consumption by $8.5 \%$. That is, the energy industry is working to reduce its own costs. However, the need for financial resources for the industry is objective, since investments are needed in the modernization of fixed assets. Stability in this industry is today the most important component of the financial basis of the state and maintaining its competitiveness in the energy export market.

\section{Conclusion}

The problems of energy security considered by the authors in this article were investigated on the basis of a system-structural approach, which made it possible, on the one hand, to determine the place of the industry in solving national security problems, and on the other hand, to identify the main threats generated by individual subsystems for ensuring energy security. According to the analysis, the most important way to solve the problem of increasing the level of energy security is to expand the participation of the state in project financing of the industry. Moreover, this support can be based not only on direct financing of projects for the modernization of the industry, but also on expanding the participation of the banking sector in this process, including through the proven mechanism of syndicated lending to the industry and subsidies from the budget to reduce interest rates on investment loans. The country has adopted a program for the modernization of the fuel and energy system for 10 years and costs of 1.3 trillion rubles. During the period of modernization, $40 \mathrm{GW}$ of capacities should be subjected to modernization. At the same time, a prerequisite is the development and use of domestic innovative solutions and domestic high-tech equipment in the framework of modernization.

The time factor is a serious risk factor in resolving this issue. According to the authors, it is the question of time that is now on the agenda in connection with research in the field of alternative energy. Alternative energy produces a renewable resource that can replace electrical energy generated from traditional resources such as oil, natural gas and coal. The increased interest in the possibilities of alternative sources of electricity is due to both environmental and economic benefits expected in the future. Although the excessively high capital costs for its creation and development are today a problem for the widespread transition to alternative energy sources in comparison with the traditional electric power industry. For example, calculations have shown that for the installation of a solar power plant with a capacity of $1000 \mathrm{MW}$, expensive mirrors with a total coverage area of about 4 square $\mathrm{km}$ are required. Also, alternative energy is characterized by low capacity, which is not able to cover the needs of business entities or the population.

For our country, alternative energy cannot play a significant role (according to forecasts, its share by 2030 will not exceed $5 \%$ ), precisely because of the above-mentioned competitive advantages of the state based on rich deposits, which sometimes not yet sufficiently explored. Nevertheless, the interest in renewable energy sources from other states that do not have such natural resources (for example, the EU countries are actively adopting energy decarbonization programs) is becoming a serious challenge for our country today trying to solve the problem of increasing the competitiveness of traditional energy. Thus, the focus on the strategy of a technological breakthrough in this industry allows traditional energy to remain the basis for solving the problems of energy supply to other industries not only in our country, but also in the world for several decades. Considering the role of this industry in budget revenues and its export orientation, we should not waste time solving these problems of the industry. Ultimately, the speed of decision-making and their effectiveness determine the financial and economic security of the state. 


\section{References}

1. E. Karanina, K. Kartavyh, Business Technologies for Sustainable Urban Development (SPbWOSCE 2017) (2017)

2. E. Karanina, L. Yurieva, E. Dolzhenkova, Espacios, 39, 28 (2018)

3. I.A. Sergeeva, Modern economy: problems and solutions, 8 (116), 64 (2019)

4. E. Karanina, O. Ryazanova, N. Gritsuk, Environmental Science for Construction Industry, 193, 8 (2018)

5. G. Klychova, A. Zakirova, A. Dyatlova, A. Klychova, E. Zaugarova, N. Zalyalova, Innovative Technologies in Environmental Science and Education (ITESE-2019), 135, 13, (2019)

6. N. Yu. Azarenko, International scientific research journal, 10 (64), 70 (2017)

7. G. A Aleksandrov, Economic relations, 3, 2269 (2019)

8. G. Dyakova, S. Izmaylova, A. Mottaeva, E. Karanina, IOP Conference Series: Earth and Environmental Science: 19th International Scientific Conference on Energy Management of Municipal Transportation Facilities and Transport (EMMFT 2017) (2017)

9. N. Ilysheva, E. Karanina, E. Baldesku, U. Zakirov, Montenegrin Journal of Economics, 13(4), 19 (2017)

10. Krause, Bossel, Müller-Reißmann, Energiewende, Wachstum und Wohlstand ohne Erdöl und Uran (1980)

11. A.A. Makarov, T.A. Mitrova, V.A. Kulagin, Global and Russian Energy Outlook, Forecast of energy development in the world and in Russia (2019)

12. Government of the Russian Federation, Analytical Center, Department of Fuel and Energy Complex and Housing and Communal Services, https://ac.gov.ru/ 